\title{
Adjustment in women treated for rheumatoid arthritis
}

\author{
Mariola Janiszewska ${ }^{1, A, D, F}{ }^{\circ}$, Bartłomiej Drop ${ }^{1, B, D \oplus}{ }^{\circ}$ Katarzyna Drop ${ }^{2, E \oplus}$, Wioleta Kowalska ${ }^{3, D, F}$, \\ Ilona Podstawka ${ }^{4, F}$, Urszula Religioni ${ }^{5, F} \odot$ \\ ${ }^{1}$ Department of Informatics and Medical Statistics with E-learning Lab, Medical University, Lublin, Poland \\ ${ }^{2}$ Department of Language, Rhetoric and Media Law, Institute of Journalism and Management, John Paul II Catholic \\ University, Lublin, Poland \\ ${ }^{3}$ Department of Clinical Immunology, Medical University, Lublin, Poland \\ ${ }^{4}$ Independent Public Clinical Hospital No. 4, Lublin, Poland \\ ${ }^{5}$ School of Economics, Warsaw, Poland \\ A - Research concept and design, B - Collection and/or assembly of data, C - Data analysis and interpretation, \\ $D$ - Writing the article, $E$ - Critical revision of the article, $F$ - Final approval of article
}

Janiszewska M, Drop B, Drop K, Kowalska W, Podstawka I, Religioni U. Adjustment in women treated for rheumatoid arthritis. Ann Agric Environ Med. 2022; 29(1): 80-85. doi: 10.26444/aaem/133369

\begin{abstract}
Introduction. The favourable or unfavourable process of a patient's adaptation to a challenging medical condition may indicate that certain adjustment reactions, which can be either constructive or undesirable, tend to prevail.

Objective. The aim of the study was to examine the adjustment reactions of patients, and to define the correlation between the reactions and socio-demographic factors, health self-assessment, satisfaction with medical care, duration of treatment, and limitations in women treated for rheumatoid arthritis.

Materials and method. The study was conducted at the Department of Rheumatology and Connective Tissue Diseases and the Specialist Outpatient Clinic of the Independent Public Teaching Hospital No. 4 in Lublin, Poland. The Polish adaptation of the Reactions to Impairment and Disability Inventory RIDI (H. Livneh, R. Antonak, 1990) was used in the study, together with an Original Questionnaire. A p-value of $<0.05$ was set to define statistical differences. Analysis was performed using commercial SPSS Statistics software (IBM Corp., Armonk, NY).

Results. Adjustment reactions, adaptive reactions, i.e. adjustment ( $3 \pm 0.5)$ and acknowledgement (2.6 \pm 0.4$)$ were found to markedly prevail, while the lowest mean value was observed for denial (1.9 \pm 0.4$)$, which was considered a negative reaction. Longer duration of the disease was associated with a lower level of external hostility. Low health self-assessment and significant limitations impairing everyday activities, caused by pain, deformity and impaired joint mobility, were mostly related to unfavourable early and intermediate non-adaptive reactions.

Conclusions. Knowledge of the adjustment reactions and their moderating factors appears to be crucial in the planning of measures aimed at the rehabilitation of RA patients.
\end{abstract}

Key words

rheumatoid arthritis, psychosocial adaptation, adjustment reactions, disability

\section{INTRODUCTION}

Rheumatoid arthritis (RA) is an autoimmune systemic connective-tissue disorder which leads to severe disability and premature mortality. The disease is characterised by progressive synovitis in symmetrical joints, and the occurrence of extra-articular lesions and systemic complications $[1,2,3]$. The clinical manifestations of symmetrical joint involvement include arthralgia, swelling, redness, and even limiting the range of motion. Early diagnosis is considered as the key improvement index for the most desirable outcomes (i.e., reduced joint destruction, less radiologic progression, no functional disability, and disease modifying anti-rheumatic drugs (DMARD)-free remission), as well as cost-effectiveness, as the first 12 weeks after early occurrence of symptoms is regarded as the optimal therapeutic window $[4,5,6]$.

Adjustment to living with rheumatoid arthritis is a longlasting process, which is associated with stress, irritation, and

Address for correspondence: Mariola Janiszewska, Department of Informatics and Medical Statistics with E-learning Lab, Medical University, Jaczewskiego 4 20-954 Lublin, Poland

E-mail: mariola.janiszewska@gmail.com

Received: 02.11.2020; accepted: 14.02.2021; first published: 05.03.2021 non-acceptance of one's health status. Due to strenuous pain and disability, RA can make patients withdraw from social life, opt for isolation, become dependent on other people, and become depressed. However, individual RA patients react differently to the limitations arising from their chronic disease and disability [7, 8].

Psychosocial adaptation, in the case of a disease or disability, is a multi-dimensional, dynamic and hierarchical process which consists of gradually attempting to achieve the best-possible match between one's own capabilities and the social and environmental requirements. This process involves the patient's displaying certain adjustment reactions, which might be adaptive or non-adaptive, from typical non-adjustment reactions to clearly adaptive responses. Adjustment and non-adjustment reactions include specific ways of reacting to the limitations and the difficult situations associated with them, which manifest themselves in the adaptation process. Early non-adaptive reactions include shock, anxiety and denial. Intermediate non-adaptive reactions include depression, internal anger and external hostility. Late adaptive reactions include acknowledgement and adjustment, i.e. coming to terms with/accepting the disease and disability. It is worth stressing that the manner 
in which an individual reacts is not typically staged, and that adjustment reactions can intertwine with non-adjustment responses [8]. The configuration of reactions, classified as early, intermediate and late, depends on a number of patientrelated and environmental conditions, and their interactions. Therefore, non-adjustment reactions often form part of the psychosocial adaptation process, and coexist with reactions of a positive and constructive nature [9]. The course of the patient's adaptation can be either favourable or unfavourable, depending on which adjustment reactions predominate. On the one hand, when desirable reactions taking the form of cognitive acknowledgement (acknowledgement) or the affective-behavioural form (adjustment) appear prevalent, this results in positive adaptation This is reflected in the patient's perception of the limitations related to the disease and disability as part of the self-image, while at the same time not giving up on the social role $[10,11]$. On the other hand, the intensification of negative reactions, such as shock, anxiety, denial and depression, reflects the so-called negative or unsuccessful adaptation, and the prevalence of such reactions is indicative of unfavourable adaptive effects.

In conclusion, patients suffering from a chronic disease tend to develop certain reactions to their condition. Favourable reactions facilitate the shaping of a proper attitude to the disease, the willingness to take up appropriate treatment, and adjustment to the new health status $[12,13,14]$.

\section{OBJECTIVE}

The aim of the study was to examine adjustment reactions, and to define the correlation between the reactions and the socio-demographic factors, health self-assessment, satisfaction with medical care, duration of treatment, and limitations related to the disease in women treated for rheumatoid arthritis.

\section{MATERIALS AND METHOD}

The study was conducted at the Department of Rheumatology and Connective Tissue Diseases and of the Specialist Outpatient Clinic of the Independent Public Teaching Hospital No. 4 in Lublin, eastern Poland, in the period from January 2017 - May 2017. The study participants were 149 women treated for rheumatoid arthritis (mean age $-60 \pm 9$, range $-45-83$ years). The inclusion criteria were as follows: - undergoing treatment for rheumatoid arthritis;

- being 45 years old or older;

- living in the Lublin macro-region;

- granting consent to participate in the study.

Exclusion criteria: lack of consent to participate in the study.

The authors utilised two research instruments:

1) The Original Questionnaire, made of two parts. The first part contained a personal information section with questions on the subject of the study - socio-demographic data. The second part featured open-ended and closeended questions, aimed at providing information in the analysed area. The duration of RA treatment, the degree to which the ailments limited everyday functioning, health self-assessment and satisfaction with medical care were determined using individual questions included in the Original Questionnaire. The reference information was collected during interviews conducted individually with each of the patients, as they filled out the questionnaire.

2) The Adaptive Responses Inventory Questionnaire by $\mathrm{H}$. Livneh and R. F. Antonak, Polish adaptation by J. Kirenko and S. Byra, which is the Polish adaptation of the Reactions to Impairment and Disability Inventory RIDI [12], was used in the study. The authors obtained consent for the use of the Adaptive Responses Inventory Questionnaire which consists of 60 items facilitating the measurement of individual reactions to becoming disabled, or contracting a chronic disease. Each statement is scored on a 4-point scale, from 1 - reaction was never experienced, to 4 reaction experienced repeatedly, more than 10 times per month. The obtained results were summed-up, and the derived value indicated the global reaction of the studied individual. The Questionnaire is composed of 8 subscales which express various categories of adjustment reactions, i.e. shock, anxiety, denial, depression, internal anger, external hostility, acknowledgement and adjustment. A higher score on a given subscale indicates a higher frequency of a specific adjustment reaction being displayed. Dividing the subscale score by the number of statements it encompasses makes it possible to compare the strength of individual responses in the studied individuals $[8,12]$. Cronbach's-alpha values for individual subscales ranged from $0.78-0.88$, being the weakest for the 'depression' subscale and the highest for the 'adjustment' subscale [8].

The duration of RA treatment, the degree to which the ailments limited everyday functioning, health self-assessment and satisfaction with treatment, were determined using the Original Questionnaire.

Ethical issues. The study was conducted in accordance with the human research principles in the Helsinki Declaration. The study was voluntary, and each participant signed a consent form and was assured that the study was anonymous. The purpose of the study was explained to the respondents and how they should independently complete questionnaires, accompanied by one of the researchers who helped them with answers in the case of any difficulties.

Statistical analysis. Continuous data were reported as means \pm SD and as the minimum-maximum range. Before parametric tests were applied, assumptions on the normality of distribution were verified by means of the Shapiro-Wilk test. The Student's t-test was applied to examine whether there were any statistical differences in terms of the ratio variables between the two groups. Spearman's rho was applied to evaluate whether there were any statistically significant correlations between the rank variables and the ratio variables. A p-value of $<0.05$ defined the statistical significance of differences. In order to compare the individual adjustment reactions, the results for each response were averaged on a scale of $1-4$. Analysis was performed using commercial SPSS Statistics 19 software (IBM Corp., Armonk, NY, USA). 


\section{RESULTS}

The study involved 149 women treated for rheumatoid arthritis mean age $-60 \pm 9$, range $-45-83$ years). Slightly more than half of the respondents (51\%) lived in rural areas. The majority $(60.4 \%)$ were in a relationship (marriage or partnership), $22.1 \%$ were widowed, $11.4 \%$ were divorced, and $6 \%$ were singles. Nearly half of the study participants had attained secondary education (45.6\%), every fourth respondent had attained higher education $(26.2 \%)$, and every fifth (19.5\%) vocational or primary (8.7\%) education. When asked about their economic status, more than half of the respondents $(66.4 \%)$ stated that they had to be frugal. Approximately $16 \%$ of the women were able to save money, $10.7 \%$ of the study participants had only sufficient money to cover their basic needs or had debts, and $6.7 \%$ did not have sufficient financial resources.

More than half of the respondents (56.4\%) had been undergoing treatment for rheumatoid arthritis for 1-5 years, $38.9 \%$ for more than 5 years, and only $4.7 \%$ for a period of time shorter than one year. Pain mostly involved the small joints of the hands and the knee joint (59.1\%), as well as the joints of the feet and the ankle joints (47\%). Every fifth respondent complained about elbow pain (20.8\%) or hip (18.8\%). Ailments associated with the disease limited the respondents' capacity to perform everyday activities to a moderate extent (55\%) or to a large extent (43\%), or made it impossible to perform numerous activities (7\% of respondents). When asked about the ailments which limited their ability to function normally, the respondents most often referred to joint pain (65.1\%), joint rigidity and deformity (32.2\%), and morning stiffness and contractures (28.8\%). Most women were afraid of losing their independence due to the disease (62.4\%). Approximately $56 \%$ were afraid of pain and suffering, $55.7 \%$ of premature death, and $32.2 \%$ of adverse reactions associated with pharmacotherapy. Regarding self-assessment of their health status, $48.3 \%$ of the studied individuals described their health as 'good' or 'very good', while $51.7 \%$ as 'bad' or 'very bad'. Only slightly more than half of the women $(54.4 \%)$ were satisfied or very satisfied with medical care, while the remainder were dissatisfied.

The predominance of certain adjustment reactions, whether negative or desirable, impacted on the course and success of the process of adapting to disability in the studied women afflicted with RA. In order to compare the individual adjustment reactions, the results for each subscale were averaged within the range of 1-4.

Statistical analysis of the mean values indicated that desirable reactions were markedly prevalent. These include affective-behavioural acceptance, such as adjustment (score $3 \pm 0.5$ points) and cognitive recognition (acknowledgement) (mean score $-2.6 \pm 0.4$ points), which proves the positive adaptation in the studied individuals who had to face the disease and disability. The lowest mean value was observed for denial (mean score $-1.9 \pm 0.4$ ), categorised under early non-adaptive reactions. Other early and intermediate nonadaptive reactions were recorded at levels similar to that of denial (Tab. 1).

No correlation was found between the place of residence and adjustment reactions of the majority of respondents. Regarding one of the early non-adaptive reactions (depression), residents of rural areas obtained significantly higher values $(\mathrm{p}<0.004)$ than residents of urban areas.
Table 1. Adjustment reactions among all the respondents

\begin{tabular}{lc}
\hline Adjustment reactions & SD (min-max) \\
\hline Shock & $2.3 \pm 0.6(1-3.1)$ \\
\hline Anxiety & $2.1 \pm 0.5(1-3.1)$ \\
\hline Denial & $1.9 \pm 0.4(1-3.4)$ \\
\hline Depression & $2.2 \pm 0.5(1-3)$ \\
\hline Internal anger & $2.2 \pm 0.5(1-3.4)$ \\
\hline External hostility & $2.2 \pm 0.4(1-3.1)$ \\
\hline Acknowledgement & $2.6 \pm 0.4(1-3.4)$ \\
\hline Adjustment & $3 \pm 0.5(1-4)$ \\
\hline
\end{tabular}

Data are means $\pm S D$ (min-max range)

Analysis of the correlation between adjustment reactions and the respondents' level of education demonstrated that the higher the level of attained education, the weaker the late positive adaptation reaction of acknowledgement $(\mathrm{p}<0.047)$. The level of education had no impact on the negative reactions, such as anxiety and external hostility ( $\mathrm{p}>0.05)$.

Single women were characterised by significantly lower acknowledgement levels than married women and those in informal relationships $(\mathrm{p}<0.028)$.

Statistical analysis did not reveal any statistically significantly correlation between financial situation and adjustment reactions of the studied individuals ( $p>0.05$ ).

The analysis indicated that women who had suffered from RA for up to 5 years displayed a markedly higher level of external hostility $(\mathrm{p}<0.032)$, categorised under intermediate non-adaptive reactions, compared to those women who had been afflicted with RA for more than 5 years.

The respondents who stated that joint pain significantly limited their everyday functioning obtained significantly higher mean values as regards unfavourable reactions, such as anxiety $(\mathrm{p}<0.028)$ and depression $(\mathrm{p}<0.040)$, when compared to the other women. Whereas no statistically significant differences were observed for acknowledgement ( $p>0.05)$ (Tab. 2).

Table 2. Adjustment reactions and everyday functioning significantly limited by joint pain

\begin{tabular}{|c|c|c|c|c|c|c|}
\hline \multirow{3}{*}{ Adjustment reactions } & \multicolumn{4}{|c|}{ Joint pain } & \multirow{2}{*}{\multicolumn{2}{|c|}{ Student's t-test }} \\
\hline & \multicolumn{2}{|c|}{ No } & \multicolumn{2}{|c|}{ Yes } & & \\
\hline & M & SD & M & SD & $\mathrm{T}$ & $\mathrm{p}<$ \\
\hline Shock & $2.2 \pm$ & 0.6 & $2.3 \pm$ & 0.5 & -1.105 & Ns \\
\hline Anxiety & $2 \pm$ & 0.5 & $2.1 \pm$ & 0.4 & -2.222 & 0.028 \\
\hline Denial & $1.8 \pm$ & 0.4 & $1.9 \pm$ & 0.4 & -0.686 & Ns \\
\hline Depression & $2.1 \pm$ & 0.6 & $2.3 \pm$ & 0.5 & -2.069 & 0.040 \\
\hline Internal anger & $2.2 \pm$ & 0.5 & $2.3 \pm$ & 0.5 & -1.112 & Ns \\
\hline External hostility & $2 \pm$ & 0.5 & $2.1 \pm$ & 0.4 & -1.515 & Ns \\
\hline Acknowledgement & $2.5 \pm$ & 0.4 & $2.6 \pm$ & 0.4 & -1.859 & Ns \\
\hline Adjustment & $2.9 \pm$ & 0.6 & $3 \pm$ & 0.4 & -1.533 & Ns \\
\hline
\end{tabular}

Data are means $\pm S D$, Student's t-test

In the case of pain, the studied women who claimed that joint deformities significantly limited their daily functioning obtained significantly higher mean values for undesirable early non-adaptive reactions, such as shock $(\mathrm{p}<0.003)$ and anxiety $(\mathrm{p}<0.013)$, and for intermediate non-adaptive reactions, such as depression $(\mathrm{p}<0.011)$, internal anger 
Table 3. Adjustment reactions and everyday functioning significantly limited by joint deformities

\begin{tabular}{|c|c|c|c|c|c|c|}
\hline \multirow{3}{*}{ Adjustment reactions } & \multicolumn{4}{|c|}{$\begin{array}{l}\text { Joint rigidity } \\
\text { and deformities }\end{array}$} & \multicolumn{2}{|c|}{ Student's t-tes } \\
\hline & \multicolumn{2}{|c|}{ No } & \multicolumn{2}{|c|}{ Yes } & \multirow[b]{2}{*}{$\mathrm{t}$} & \multirow[b]{2}{*}{$\mathrm{p}<$} \\
\hline & M & SD & $M$ & SD & & \\
\hline Shock & $2.2 \pm$ & 0.6 & $2.5 \pm$ & 0.4 & -2.998 & 0.003 \\
\hline Anxiety & $2 \pm$ & 0.5 & $2.2 \pm$ & 0.3 & -2.502 & 0.013 \\
\hline Denial & $1.9 \pm$ & 0.5 & $1.9 \pm$ & 0.3 & -0.384 & ns \\
\hline Depression & $2.2 \pm$ & 0.6 & $2.4 \pm$ & 0.4 & -2.582 & 0.011 \\
\hline Internal anger & $2.1 \pm$ & 0.5 & $2.4 \pm$ & 0.4 & -3.074 & 0.003 \\
\hline External hostility & $2 \pm$ & 0.5 & $2.2 \pm$ & 0.3 & -2.846 & 0.005 \\
\hline Acknowledgement & $2.5 \pm$ & 0.5 & $2.6 \pm$ & 0.4 & -0.842 & ns \\
\hline Adjustment & $2.9 \pm$ & 0.5 & $3 \pm$ & 0.4 & -1.073 & ns \\
\hline
\end{tabular}

Data are means \pm SD, Student's t-test

$(\mathrm{p}<0.003)$ and external hostility $(\mathrm{p}<0.005)$, compared to the individuals who saw no such limitations (Tab. 3).

Similar to the data presented in Tables 2 and 3, the respondents who claimed that impaired joint mobility significantly limited their everyday functioning obtained markedly higher mean values for negative non-adaptive reactions, including early and intermediate responses, such as shock, $(\mathrm{p}<0.001)$, anxiety $(\mathrm{p}<0.001)$, depression $(\mathrm{p}<0.001)$, internal anger $(\mathrm{p}<0.001)$, and external hostility $(\mathrm{t}=6.101$; $\mathrm{p}<0.001)$, but also in respect of constructive reactions, such as acknowledgement $(\mathrm{p}<0.001)$ and adjustment $(\mathrm{p}<0.004)$, when compared to the other studied respondents (Tab. 4).

Table 4. Adjustment reactions and everyday functioning significantly limited by impaired joint mobility

\begin{tabular}{|c|c|c|c|c|c|c|}
\hline \multirow{3}{*}{ Adjustment reactions } & \multicolumn{4}{|c|}{ Impaired joint mobility } & \multirow{2}{*}{\multicolumn{2}{|c|}{ Student's t-test }} \\
\hline & \multicolumn{2}{|c|}{ No } & \multicolumn{2}{|c|}{ Yes } & & \\
\hline & $M$ & SD & $M$ & SD & $t$ & $\mathrm{p}<$ \\
\hline Shock & $1.7 \pm$ & 0.6 & $2.4 \pm$ & 0.5 & 5.658 & 0.001 \\
\hline Anxiety & $1.7 \pm$ & 0.4 & $2.2 \pm$ & 0.4 & 5.008 & 0.001 \\
\hline Denial & $1.8 \pm$ & 0.6 & $1.9 \pm$ & 0.4 & 1.154 & ns \\
\hline Depression & $1.5 \pm$ & 0.4 & $2.4 \pm$ & 0.4 & 7.916 & 0.001 \\
\hline Internal anger & $1.7 \pm$ & 0.4 & $2.3 \pm$ & 0.5 & 6.000 & 0.001 \\
\hline External hostility & $1.6 \pm$ & 0.4 & $2.2 \pm$ & 0.4 & 6.101 & 0.001 \\
\hline Acknowledgement & $2.2 \pm$ & 0.6 & $2.6 \pm$ & 0.4 & 4.126 & 0.001 \\
\hline Adjustment & $2.7 \pm$ & 0.8 & $3 \pm$ & 0.4 & 2.926 & 0.004 \\
\hline
\end{tabular}

Data are means $\pm S D$, Student's t-test

As revealed by the statistical analysis, self-assessment of one's health status differentiated the adjustment reactions of the studied women suffering from rheumatoid arthritis. The respondents who assessed their health as 'bad' or 'very bad' were characterised by significantly higher mean values for negative non-adaptive reactions, such as anxiety $(\mathrm{p}<0.042)$ and internal anger $(\mathrm{p}<0.032)$, compared to the women who assessed their health as 'good' or 'very good'. Health selfassessment is a significant indicator of the health condition as it reflects the physical, mental, functional and social health condition of a person.

Low health self-assessment of the respondents was probably determined by arduous health problems, which could cause anxiety in those persons about the future, and inner anger concerning the situation. Significant health problems most frequently determined the need for help from the environment and withdrawal from professional activity, which can also be a reason for perceived helplessness. People with low selfassessment of own health significantly more often tended to orient toward emotions in the face of experienced difficult situations, showing non-adaptive reactions. No statistically significant differences were observed for shock, nor for denial, depression, external hostility, acknowledgement and adjustment ( $\mathrm{p}>0.05$; Tab. 5).

Table 5. Adjustment reactions vs. health self-assessment

\begin{tabular}{lcccc}
\hline \multirow{2}{*}{ Adjustment reactions } & \multicolumn{2}{c}{ How would you assess your health } & \\
& \multicolumn{2}{c}{ status? } & \multirow{2}{*}{ Student's t-test } \\
\cline { 2 - 4 } & Very good/good & Very bad/bad & & \\
\hline Shock & $2.2 \pm 0.6$ & $2.4 \pm 0.5$ & -1.666 & $\mathrm{~ns}$ \\
\hline Anxiety & $2 \pm 0.5$ & $2.2 \pm 0.4$ & -2.051 & 0.042 \\
\hline Denial & $1.8 \pm 0.4$ & $1.9 \pm 0.4$ & -1.579 & $\mathrm{~ns}$ \\
\hline Depression & $2.2 \pm 0.6$ & $2.4 \pm 0.5$ & -1.356 & $\mathrm{~ns}$ \\
\hline Internal anger & $2.1 \pm 0.5$ & $2.3 \pm 0.5$ & -2.161 & 0.032 \\
\hline External hostility & $2 \pm 0.5$ & $2.1 \pm 0.4$ & -1.114 & $\mathrm{~ns}$ \\
\hline Acknowledgement & $2.5 \pm 0.5$ & $2.5 \pm 0.4$ & -0.749 & $\mathrm{~ns}$ \\
\hline Adjustment & $2.9 \pm 0.5$ & $2.9 \pm 0.5$ & -0.006 & $\mathrm{~ns}$ \\
\hline
\end{tabular}

Data are means $\pm S D$, Student's t-test

Satisfaction with medical care was not found to significantly differentiate the respondents in terms of their adjustment reactions to the disease and disability. The only statistically significant difference was recorded for adjustment, being a positive adaptive reaction $(\mathrm{p}<0.021)$, with markedly higher mean values achieved for those women who were very satisfied or moderately satisfied with medical care, when compared to those expressing their dissatisfaction.

\section{DISCUSSION}

An attempt was made in the current study to present the significant issue of adjustment to rheumatoid arthritis, indicating various reactions of women suffering from RA. This is undoubtedly an extremely important issue, although it has rarely been raised in the literature. The theoretical aim of the study was original; the cognitive aim was to describe a phenomenon that had not been previously described in the literature, to fill the existing gap, and to open further opportunities for investigation and issues arising.

Adjusting to living with disability is a long-lasting and difficult process faced by individuals who have sustained physical harm, or have become disabled. This process includes various reactions of the afflicted person towards the objective changes caused by disability, which determine his or her behaviour, as well as subjective perception of the present and future prospects of life.

It should be noted that the women treated for rheumatoid arthritis were much more frequently found to display positive reactions, such as adjustment to the limitations associated with the disease and acknowledgement of the disease. Livneh and Martz [9] claimed that when considered jointly, 
acknowledgement and adjustment should be regarded as indicators of positive adaptation to a disease and disability In this study, denial was the found to constitute the least frequently observed reaction. Also, other non-adaptive reactions, such as shock, anxiety, depression, internal anger and external hostility, were at similar levels to denial. Therefore, desirable adaptive reactions, associated with the correct course of psychosocial adaptation, were found to prevail. Acknowledging the situation at hand and ultimately adjusting to it were most often observed. Livneh [9] indicated that the adaptive reactions displayed by chronically-ill or disabled people might be related to general psychosocial well-being. The fact of displaying favourable adjustment reactions is treated as coexisting with the indicators of a desirable and satisfying quality of life in the intrapersonal domain, such as life satisfaction and health. In turn, negative reactions which do not facilitate psychosocial adaptation, or can even hamper it, are treated as factors associated with a lower quality of life $[12,13]$.

In the current study, attention was paid to the correlation between adjustment reactions and a range of variables related to the health status of a person afflicted with a disease or disability. Significant limitations impairing everyday activities, caused by pain, deformity and impaired joint mobility, are mostly related to unfavourable early and intermediate non-adaptive reactions. The respondents who stated that joint pain significantly limited their everyday activities and functioning were more often characterised by anxiety and depression, with the only differences close to attaining the level of statistical significance recorded for the acknowledgement of disability. Other authors also indicate that RA often affects people in the most active period of their lives, and that the unpredictable and painful course of this disease often leads to serious secondary consequences, such as depression, limited social activity and loss of one's job $[15,16]$. The study also revealed that the respondents whose functioning had been affected by joint deformities and impaired joint mobility were more inclined to react with shock, anxiety and depression, and displayed both internal anger and external hostility. Constructive adjustment reactions, such as acknowledgement and adjustment, were found only in the women who complained about the limitations related to impaired joint mobility. According to other authors, contracting RA results in many negative thoughts and emotions, and the ways of reacting to them could lead to various patterns of behaviour $[17,18]$.

On the one hand, when experiencing severe pain, patients can display a propensity to denial, which results in a reduced quality of life [19]. On the other hand, the literature also contains findings which suggest that people struggling with a disease can focus on finding a way of living with pain and eventually accepting it, which allows them to adjust to their new health status [20]. Acknowledgement can therefore be regarded as a process in which patients begin to make choices which maximise their quality of life, and facilitate successful coping with the consequences of the disease [21,22]. Patients who had come to terms with their pain were better able to cope with the ailment and everyday problems, achieve better therapeutic results, and more rarely displayed symptoms of depression $[23,24]$.

Subjective health assessment is an important variable when it comes to the shaping of adjustment reactions in a chronic disease and disability. In the course of this independent study, the low self-assessment of the health status contributed to clearly non-adaptive reactions, reflected in the anxiety experienced due to falling ill, and internal anger, i.e., resentment and bitterness. Differences which were close to attaining the level of statistical significance also pertained to shock, observed mainly in the initial phase of the adaptive process. This, however, does not mean that early reactions cannot manifest themselves later in the course of the disease. Livneh and Antonak [25] claimed that such later manifestation could be due to certain stimuli which are directly or indirectly associated with the effects of the disability, and are so strong that they can again disrupt the temporarily restored psychosocial balance. Non-adaptive reactions, which form part of the adaptation process, intermingle with development-oriented responses [25]. However, no interrelation was observed between the respondents' health self-assessment and the adaptive reactions. Currently, subjective health assessment is being more frequently taken into account in the analyses of the psychosocial functioning of people struggling with a disease or disability. This is due to the impact of health self-assessment on the quality-of-life indicators, objectiveoriented activities, health-enhancing behaviour patterns, and motivation to undergo the appropriate therapy and rehabilitation $[26,27]$.

Healthcare practitioners should play a major role in the process of the patient's adjusting not only to chronic diseases or disability, but also to rare diseases [28,29]. In the opinion of the authors of the current study, it is rather disturbing that they did not find any correlation between satisfaction with medical care in the disease process, and the respondents' displaying constructive adjustment reactions. The only difference close to attaining the level of statistical significance was recorded in the case of adjustment, with higher mean values obtained for those respondents who were satisfied with medical care, compared to those expressing dissatisfaction.

Particular attention should be paid to those patients who displayed negative non-adaptive adjustment reactions, irrespective of the adopted remedial measures. In such cases, more effective measures should be applied, and the patients should be provided with support and made aware of the positive aspects of their current health status.

The study exhibited certain constraints, including the limited number of respondents, a significant age span, and the limited area covered by the study. Therefore, it is necessary to conduct further studies covering a larger number of women living across Poland. The strength of the study is the fact that the project focused on a very significant area of adjustment reactions among women suffering from rheumatoid arthritis - a subject matter which has been underestimated and rarely taken up by scholars. Given the increase in the number of patients, adaptive reactions and actions taken independently by the patients are becoming increasingly important, since they might facilitate the development of attitudes which are beneficial to health and promote taking responsibility for one's own medical condition

Assessment of the process of adjustment to a new health situation and a correct course of this process contribute to the achievement of valuable guidance, conditioning embracement of the sick with the complex, multi-dimensional care. Patients with early arthritis should be quickly identified on the basic medical care level and immediately referred to a rheumatologist. The condition of an effective treatment is also 
a well-functioning process of adaptation to a new situation. Manifestation of adaptive responses in a desired way, e.g., starting rehabilitation, coexists with subjective health control indicators, and therefore with less sense of mental discomfort connected with the disease.

Taking into consideration that the way an individual reacts to sickness is not staged and is dependent on a variety of conditions concerning a sick person, the environment and their mutual interactions, despite the quick 'path' which is a solution intended for complex specialist care, it would be helpful to elaborate the early implementation methods of the illness acceptance process. Perhaps early dominantion of the desired adaptive reactions would contribute to greater willingness to start rehabilitation and undertake the hardships of treatment. It should be definitely remembered that rehabilitation is not only a process of physical recovering, but also - maybe even more significantly - of reintegration into society: to family, social and professional life.

The role of manifesting favourable and unfavourable adjustment reactions in the process of treatment requires further analyses. Taking into account the dynamic nature of the adapting phenomena, more complicated associations may be expected than those shown in the research. Longitudinal studies would definitely provide a better explanation of the described phenomenon.

\section{CONCLUSIONS}

1. The obtained results show that despite health problems, the respondents manifest desired reactions conducive to the optimization of functioning.

2. The knowledge of adjustment reactions and their moderating factors appears to be crucial in the planning of measures aimed at taking care of patients diagnosed with RA.

3. The negative character of associations between the variables discovered in the study suggests that such reactions as internalized anger, directing hostility towards others, or anxiety, can reduce the intensity of behaviours conductive to health, including health practices, or positive mental attitude.

\section{REFERENCES}

1. Malm K, Bremander A, Arvidsson B, Andersson ML, Bergman S, Larsson I. The influence of lifestyle habits on quality of life in patients with established rheumatoid arthritis-A constant balancing between ideality and reali-t y. Int J Qual Stud Health Well-being. 2016; 11: 30534. doi: 10.3402/qhw.v11.30534.11

2. Yunchun L, Yue W, Jun FZ, Qizhu S, Liumei D. Clinical Significance of Red Blood Cell Distribution Width and Inflammatory Factors for the Disease in Rheumatoid Arthritis. Clin Lab. 2016; 62(12): 2327-2331. doi: 10.7754/Clin.Lab.2016.160406

3. Feldthusen C, Mannerkorpi K. Factors of importance for reducing fa-tigue in persons with rheumatoid arthritis: a qualitative interview study. BMJ Open. 2019; 9(5): 2018-028719. http://dx.doi.org/10.1136/ bmjopen-2018-028719

4. Moura CS, Cristiano SM, Abrahamowicz M, Beauchamp ME, Lacaille D, Wang Y, et al. Early medication use in new-onset rheumatoid arthritis may delay joint replacement: results of a large population-based study. Arthritis Res Ther. 2015;17(1): 197 doi: 10.1186/s13075-015-0713-3

5. Guo Q, Wang Y, Xu D J, Nossent J, Pavlos J, Xu J. Rheumatoid arthritis: pathological mechanisms and modern pharmacologic therapies. Bone Res. 2018; 6(15): 1-4. doi: 10.1038/s41413-018-0016-9

6. Nazary-Moghadam S, Zeinalzadeh A, Salavati M, Almasi S, Negahban $H$. Adaptation, reliability and validity testing of a Persian version of the Health Assessment Questionnaire-Disability Index in Iranian patients with rheumatoid ar-thritis. J Bodyw Mov Ther. 2017; 21(1): 133-140. doi: 10.1016/j.jbmt.2016.07.001
7. Cho SK, Kim D, Won S, Lee J, Choi CB, Choe JY, et al. Factors associated with time to diagnosis from symptom onset in patients with early rheumatoid arthritis. Korean J Intern Med. 2019; 34(4): 910-916113. doi: $10.3904 / \mathrm{kjim} .2017 .113$

8. Byra S, Kirenko J. Kwestionariusz Reakcji Przystosowawczych (KRP) - polska adaptacja Reactions to Impairment and Disability Inventory - RIDI H. Livneha i R.F. Antonaka. Stud Eduk. 2016; 40: 229 260. doi: 10.14746/se.2016.40.14

9. Livneh H, Martz E. Coping strategies and resources as predictors of psychosocial adaptation among people with spinal cord injury. Rehabil Psychol. 2014; 59(3): 329-399. https://doi.org/10.1037/a0036733

10. King J, O’Neill B, Ramsay P, Linden MA, Darweish Medniuk A, Outtrim J, et al. Identifying patients' support needs following critical illness: a scoping review of the qualitative literature. Crit Care. 2019; 23(1): 187. doi: 10.1186/s13054-019-2441-6

11. Englbrecht M, Alten R, Aringer M, Baerwald CG, Burkhardt H, Eby $\mathrm{N}$, et al. New insights into the prevalence of depressive symptoms and depression in rheumatoid arthritis - Implications from the prospective multicenter VADERA II study. PloS One. 2019; 14(5): e0217412. https:// doi.org/10.1371/journal.pone.0217412

12. Livneh H, Lott SM, Antonak RF. Patterns of psychosocial adaptation to chronic illness and disability: a cluster analytic approach. Psychol Health Med.2004;9(4): 411-430.https://doi.org/10.1080/1354850042000267030

13. Kłak A, Mińko M, Siwczyńska D, Samoliński B. Selected questionnaire methods studying the quality of life. Post Dermatol Alergol. 2015; 32(3): 210-215. doi: $10.5114 /$ pdia.2015.48047

14. Zhou X, Wu X, Zhen R. Self-esteem and hope mediate the relations between social support and post-traumatic stress disorder and growth in adole-scents following the Ya'an earthquake. Anx Str Cop. 2018; 31(1): 32-45. https://doi.org/10.1080/10615806.2017.1374376

15. Crofford LJ. Use of NSAIDs in treating patients with arthritis. Arthritis Res Ther. 2013; 15(3): S2. doi: 10.1186/ar4174

16. Hewlett S, Almeida C, Ambler N, Blair PS, Choy EH, et al. Reducing arthritis fatigue impact: two-year randomised controlled trial of cognitive behavioural approaches by rheu-matology teams (RAFT). Ann Rheum Dis. 2019; 78(4): 465-472. doi: 10.1136/ann rheumdis-2018-214469

17. Hassan AA, Nasr MH, Mohamed AL, Kamal AM, Elmoghazy AD. Psychological affection in rheumatoid arthritis patients in relation to disease activity. Medicine, 2019; 98(19): e15373. doi: 10.1097/ MD.0000000000015373

18. Prothero L, Barley E, Galloway J, Georgopoulou S, Sturt J. The evidence base for psychological interventions for rheumatoid arthritis: A systematic re-view of reviews. Int J Nurs Stud. 2018; 82: 20-29. doi: 10.1016/j.ijnurstu. 2018.03.008

19. DiRenzo D, Crespo-Bosque M, Gould N, Finan P, Nanavati J, Bingham CO. Systematic Review and Meta-analysis: Mindfulness-Based Interventions for Rheumatoid Arthritis. Curr Rheumatol Rep. 2018; 20(12): 75. doi: 10.1007/s11926-018-0787-4

20. Kostova Z, Caiata-Zufferey M, Schulz PJ. The process of acceptance among rheumatoid arthritis patients in Switzerland: A qualitative study. Pain Res Manag. 2014; (2): 61-68. doi: 10.1155/2014/168472

21. Bandura A. Applying Theory for Human Betterment. Perspect Psychol Sci. 2019; 14(1): 12-15. https://doi.org/10.1177/1745691618815165

22. Drop B, Janiszewska M, Barańska A, Kanecki K, Nitsch-Osuch, Bogdan M. Satisfaction with Life and Adaptive Reactions in People Treated for Chronic Obstructive Pulmonary Disease. Adv Exp Med Biol. 2018; 1114: 41-47. doi: 10.1007/5584_2018_242

23. Amtmann D, Bamer AM, Nery-Hurwit MB, Liljenquist KS, Yorkston K. Factors associated with disease self-efficacy in individuals aging with a disa-bility. Psychol Health Med. 2109; 24(10): 1171-1181. https://doi. org/10.1080/13548506.2019.1612082

24. Euesden J, Matcham F, Hotopf M, Steer S, Cope AP, Lewis CM. The Relationship Between Mental Health, Disease Severity, and Genetic Risk for Depression in Early Rheumatoid Arthritis. Psychosom Med. 2017; 79(6); 638-645. doi: 10.1097/PSY.0000000000000462

25. Livneh H. Psychosocial adaptation to chronic illness and disability. Rehab Couns Bull. 2001; 44: 151-160. https://doi. org/10.1177/003435520104400305

26. Rzeszutek M, Oniszczenko W, Kwiatkowska B. Stress coping strategies, spirituality, social support and posttraumatic growth in a Polish sample of rheumatoid arthritis patients. Psych Healt Med. 2017; 22(9): 1082-1088. https://doi.org/10.1080/13548506.2017.1280174

27. Hassan A, Nasr MH, Mohamed AL, Kamal AM, Elmoghazy AD. Psychological affection in rheumatoid arthritis patients in relation to disease activity. Medicin. 2019; 98(19): e15373. doi: 10.1097/ MD.0000000000016515

28. Bogdan M, Nitsch-Osuch A, Kanecki K, Goryński P, Tyszko P, Barańska A, et al. Sarcoidosis among hospitalized patients in Poland: a study based on a national hospital registry. Pol Arch Intern Med. 2019; 129(9): 580-585. doi: 10.20452/pamw.14927

29. Tarka P, Nitsch-Osuch A, Goryński P, Tyszko P, Bogdan M, Kanecki K. Epidemiology of Pulmonary Aspergillosis in Hospitalized Patients in Poland During 2009-2016. Adv Exp Med Biol. 2019; 1160: 73-80. doi: $10.1007 / 5584 \_2019 \_347$ 